\title{
Sports, Physical Education, Olympic Games, and Brazil: The Deafness That Still Should Be Listened
}

\author{
Clévia Fernanda Sies Barboza ${ }^{1,2}$, Ana Regina Campello' ${ }^{1}$, Helena Carla Castro ${ }^{1,2,3 *}$ \\ ${ }^{1}$ Post Graduate Program in Diversity and Inclusion (CMPDI), Federal Fluminense University, Niterói, Brazil \\ ${ }^{2}$ Post Graduate Program in Bioscience and Health, Fiocruz, Rio de Janeiro, Brazil \\ ${ }^{3}$ Post Graduate Program in Science and Biotechnology (PPBI), Federal Fluminense University, Niterói, Brazil \\ Email: "hcastrorangel@yahoo.com.br
}

Received 20 October 2014; accepted 19 July 2015; published 22 July 2015

Copyright (C 2015 by authors and Scientific Research Publishing Inc.

This work is licensed under the Creative Commons Attribution International License (CC BY).

http://creativecommons.org/licenses/by/4.0/

c)

\section{Abstract}

Since the sports and health-promoting activities have become part of modern civilization, Physical Education (PE) has become an important discipline that approaches these topics to the teenagers and children. PE introduces students to a wide range of sports, their rules and their relationship with health, from elementary to higher education levels. It also helps on discovering and training athletes for the Olympic Games, Paralympic Games and Deaflympics. For teaching PE and sports to deaf students, we should use sign language. Since Brazil will hold the Olympic Games in 2016, in this work we aim to survey for signs of 33 sports of the Olympic Games in Brazilian Sign Language (LIBRAS-LSB) and to verify their linguistic consistence for teaching deaf students and help on receiving deaf visitors at the time of the Olympic Games. According to our data, among the $\mathbf{3 3}$ sports selected for this study, only $\mathbf{1 0}$ are represented in LIBRAS according to dictionary Acessibilidade Brasil (http://www.acessobrasil.org.br) from the Brazilian National Institute of Education of Deaf (INES). Importantly, some signs do not strictly follow neither the LIBRAS grammatical structure nor the visual-motor feature related to the sport represented (e.g. Athletics). Among the 23 missing sports there included the Artistic Gymnastics and Sailing in which Brazil has held good athletes. The comparison of LSB with other sign languages from United States (ASL), France (FSL) and Spain (SSL) using Spread The Sign, an international dictionary (www.spreadthesign.com), revealed that some of these inconsistence also appears in another languages. Our data points to the urgent need for creating and/or organizing the Brazilian sports signs using a formal tool such as INES dictionary for teaching PE and using them at the time of the Olympic Games in Brazil.

\section{Keywords}

Physical Education, Sports, Olympic, Deafness, Sign Language

\footnotetext{
${ }^{*}$ Corresponding author.
}

How to cite this paper: Barboza, C. F. S., Campello, A. R., \& Castro, H. C. (2015). Sports, Physical Education, Olympic Games, and Brazil: The Deafness That Still Should Be Listened. Creative Education, 6, 1386-1390. 


\section{Introduction}

According to World Health Organization "Physical activity is defined as any bodily movement produced by skeletal muscles that requires energy expenditure". Scientific data confirm that performing regular moderate intensity physical activity such as walking or participating in sports has significant benefits for health (WHO, 2015). Adequate levels of physical activity reduce the risk of cardiovascular diseases, diabetes, depression, colon and breast cancer, and help control weight. Due to its importance, the lack of physical activity is the fourth leading risk factor for global mortality leading to approximately 3.2 million deaths worldwide (WHO, 2015).

Because of these benefits, Physical Education (PE) is an important discipline as it helps the students in learning motor skills, developing fitness and gaining understanding about the role of physical activity in their lives. Importantly, students that are healthy and physically active are more likely to be academically motivated, and successful persons (Brazil, 2000; WHO, 2015).

PE classes are generally dynamic and may be especially attractive for deaf students due to their more practical and visual-spatial nature. It is important to remember that deafness does not affect neither physical nor motor development of these individuals (Ferreira, 2011). In general deafness is exclusively related to auditive sensory loss, which does not compromise the physical conditions of competing in any sporting event. In fact, some scientific data point that athletes with congenital vestibular failure is well compensated for higher level sport activities (Jin et al., 2010). Therefore, such individuals can and should participate actively in physical education also competing in events.

Since PE introduces the world of sports for all students, it helps to discover athletes to compete in events such as the Olympic, Paralympic or Deaflympics Games. These specific sporting events take place every four years and bring representatives of nations all round the world to compete according to global rules. The first International Olympics Games occurred in 1896 whereas the Paralympic version for disable people was only in 1960. The first games for deaf persons entitled The Silent Games were in 1922 now called Deaflympics.

Brazil will hold the Olympic Games in 2016, which should stimulate students, including deaf ones, to participate in sports as well as in this event as it joins people all around the world. For that purpose the use of the Brazilian Sign Language (LIBRAS) is important as it connects the deaf with this topic (Gomes, 2008). In Brazil, LIBRAS is used for teaching PE for deaf students as well as other disciplines. According to the Brazilian Law 10.436, LIBRAS is the linguistic system of the Brazilian deaf community, and has a specific grammatical structure based on a visual-motor nature. Importantly, LIBRAS is significantly different from Portuguese not only structurally, but also in grammar (Quadros \& Perlin, 2007). Portuguese is the first language of Brazilian hearing people and the second language of Brazilian deaf community (Brazil, 2002).

The aim of this research was to identify and analyze the signs in LIBRAS related to 33 Olympic sports comparing them with American (ASL), French (FSL) and Spanish (SSL) Sign languages. We also verified the visual-spatial structure of these signs and their structural compatibility with LIBRAS rules and with the sport represented. Since PE and sports involve important issues such as health and exploring professional athlete's talents, our main purpose is to contribute to the discussion about Brazil and its approach regarding sports and PE with the deaf community.

\section{Methodology}

Initially, we used the online dictionary Acessibilidade Brasil (http://www.acessobrasil.org.br) from the Brazilian National Institute of Education of Deaf (INES) to search for signs of 33 sports from the modern Olympic games, which are also part of Deaflympics including: Athletics, badminton, basketball, boxing, canoeing, cycling, fencing, football, artistic gymnastics, rhythmic gymnastics, golf, handball, equestrian, field hockey, judo, weightlifting, wrestling, synchronized swimming, swimming, modern pentathlon, water polo, rowing, rugby, diving, taekwondo, tennis, table tennis, archery, shooting sports, triathlon, sailing, volleyball and beach volleyball.

The structure of the signs was also analyzed according to LIBRAS rules that is a visual-spatial language, identifying them as arbitrary signs (non-related to form and/or movement) or iconic signs (committed with the object and action form and/or movement) (Frydrych, 2012). We also searched for these signs and compared them with the American (ASL), French (FSL) and Spanish (SSL) Sign languages present on the international online dictionary Spreadthesign (www.spreadthesign.com).

\section{Results and Discussion}

Sign languages are not a random group of signs but have their own grammatical structure (syntax, semantics, 
morphology). Their visual-spatial nature differentiates them from oral-auditory languages, demanding the correctness of the signs to allow the accurate interpretation when used for teaching purposes. Sports and Physical education present their own rules that are important to the success of teaching and/or executing them. Therefore, they need even more the correctness of these representative signs to be well understood.

In this study, we searched and analyzed the presence of signs in LIBRAS regarding 33 sports of Olympics, Paralympics and Deaflympics games. Among these 33 sports, we found only 10 signs in LIBRAS in the online dictionary Acessibilidade Brasil (http://www.acessobrasil.org.br) from INES (Figure 1).

Among the 10 signs, some are arbitrary or not strictly well represented as they do not rigorously follow LIBRAS rules. They also present low or insufficient visual-spatial consistency regarding the physical activity involved. For example, the sign Athletics presents the following sequence of signals: Athlete + Run + Jump + Several (Figure 2). This sign tries to express the complexity within the athletics modality, which is composed with running, jumping, throwing and walking activities. The current sign affects the comprehension of this sport when used in sentences such as: "He won two medals in athletics, one in throwing and another in the 100-meter running" as it refers to only running and jumping, but not the other parts (throwing and walking).

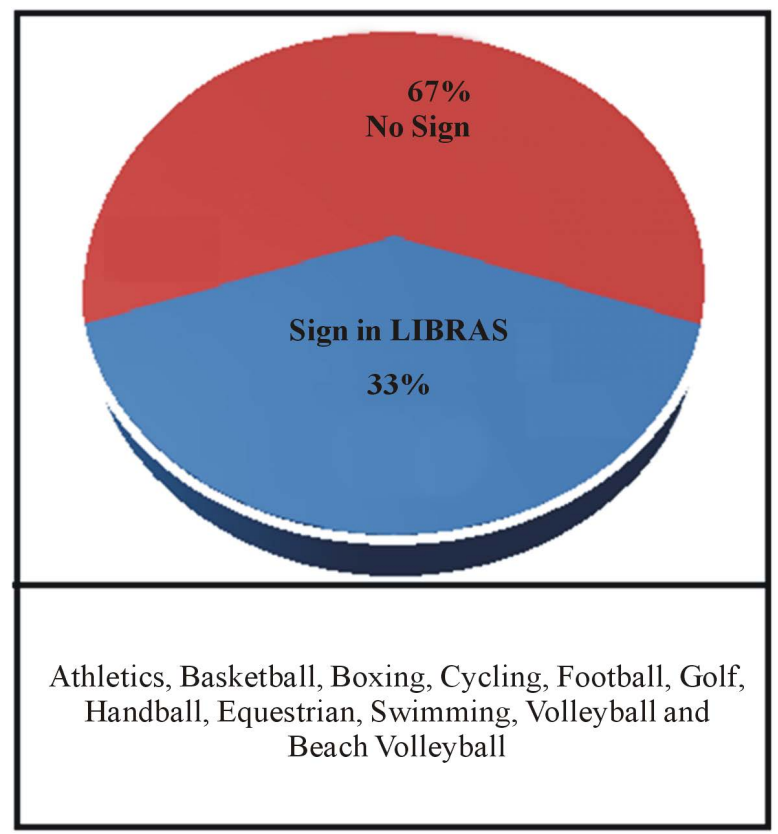

Figure 1. Percentage of signs found in LIBRAS regarding the 33 Olympics sports searched in the online dictionary Acessibilidade Brasil (http://www.acessobrasil.org.br) from the Brazilian National Institute of Education of Deaf (INES). Comparison of the amount of signs found (up), and the list of those present in the dictionary (down).
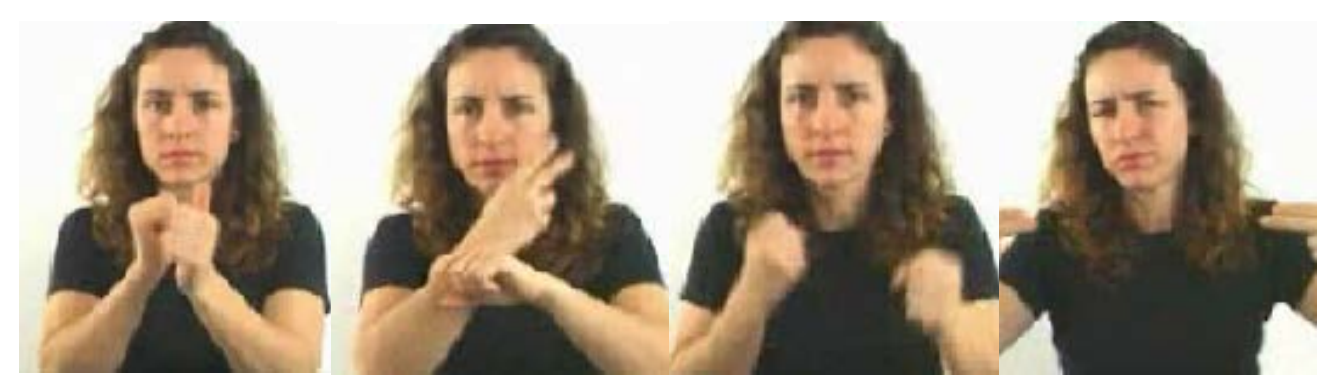

Figure 2. Sequence of the sign Athletics in LIBRAS (Athlete + Jump + Run + Several, respectively) found in the online dictionary Acessibilidade Brasil (http://www.acessobrasil.org.br) from INES. The sign sequence tries to explain the meaning of Athletics, which may lead to inaccurate interpretations of the sport since it is not a unique sign within the grammatical structure of the LIBRAS, but an incomplete representation of the sport. 
We also detected some iconic signs that do not represent correctly the movement of the sport. As an example, we may cite Boxing and Handball that represent the movement or action but without accuracy (Figure 3, left). The sign Boxing should present the proper defense in front of the face and performance of the punch movement (Figure 3, right). Similarly the sign Handball does not show the correct $90^{\circ}$ angle of the throwing motion (Figure 3, down). Probably this is due to the creation of these signs from people that do not know precisely these sports, deciding only through a simple perspective without the real concept of it.

The search for signs of these 33 Olympic sports in American (ASL), French (FSL) and Spanish (SSL) sign languages in the online dictionary SpreadTheSign revealed analogous results in terms of amount ( $\mathrm{n}=17-19)$ and sign style. Some of these words are just spelled by dactylology (manual alphabetic spelling) whereas others describe its meaning, similar to LIBRAS (Figure 4).

The comparison of the sign Boxing revealed the inconsistency regarding the proper movement and hand position, similar to LIBRAS (Figure 5). The ASL is the closest to the correct hand position regarding face defense. Since the correct hand position and movement as well as the proper representation of the subject are linguistic requirements of these sign languages, our study enlighted the importance of the participation of specialists in that matter (e.g. Physical education teacher or athlete) when creating a new sign on sports area. In addition, our study also suggest the necessity of adjusting the existing ones to a proper representation and use for teaching purpose.

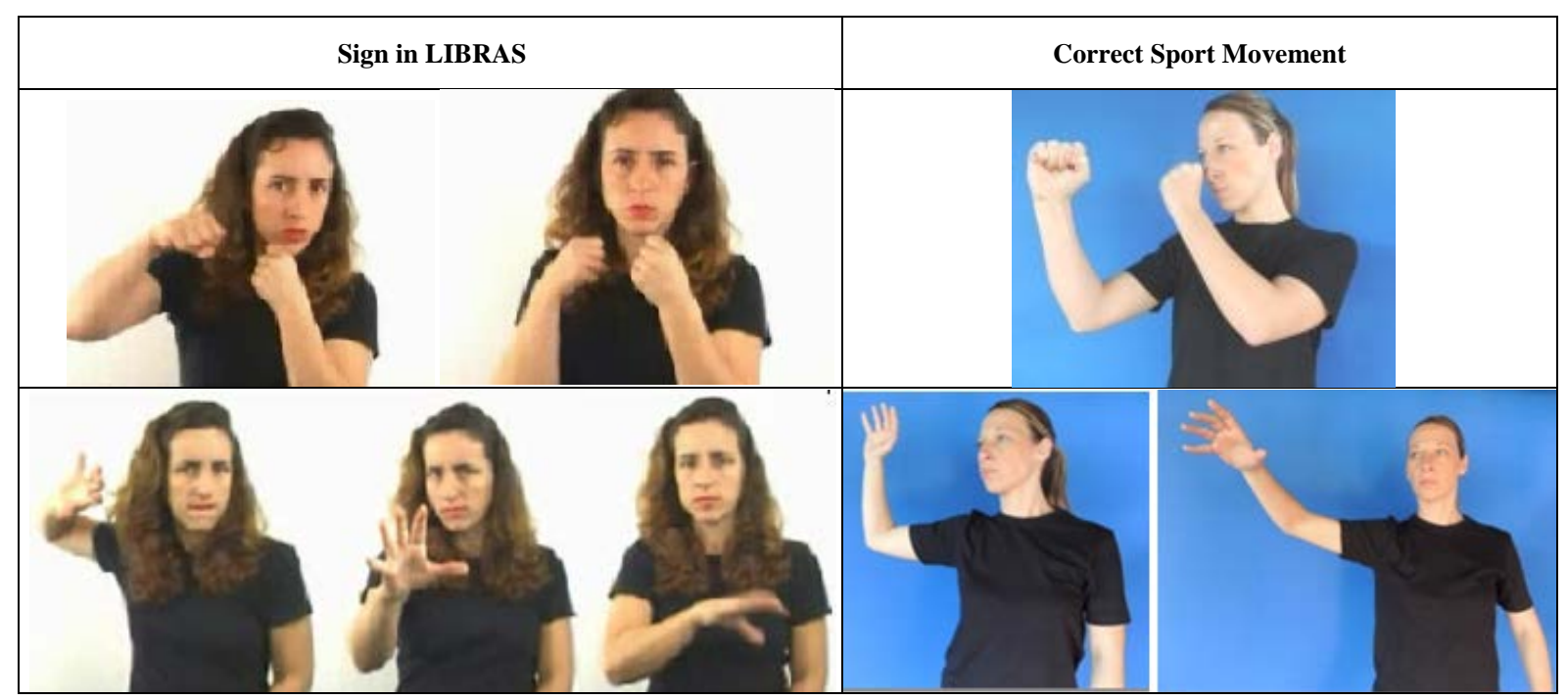

Figure 3. Sequence of the iconic signs Boxing (up) and Handball (down) in LIBRAS (left) found in the online dictionary Acessibilidade Brasil (http://www.acessobrasil.org.br) from INES. The analysis of the correct sport movement (right) revealed that these iconic signs do not present the precise movement, neither for Boxing (face defense) nor for the Handball $\left(90^{\circ}\right.$ angle position of the arm to throw).

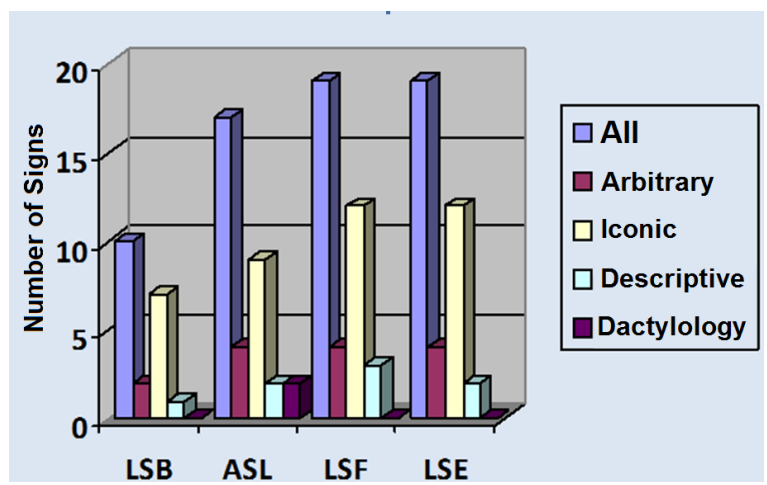

Figure 4. Comparison of the number of signs found for 33 Olympics sports in the Brazilian (LIBRAS = 10), American (ASL $=17)$, French $(\mathrm{FSL}=19)$ and Spanish $(\mathrm{SSL}=19)$ sign languages. Most signs are Iconic (yellow) and Arbitrary (brown). 


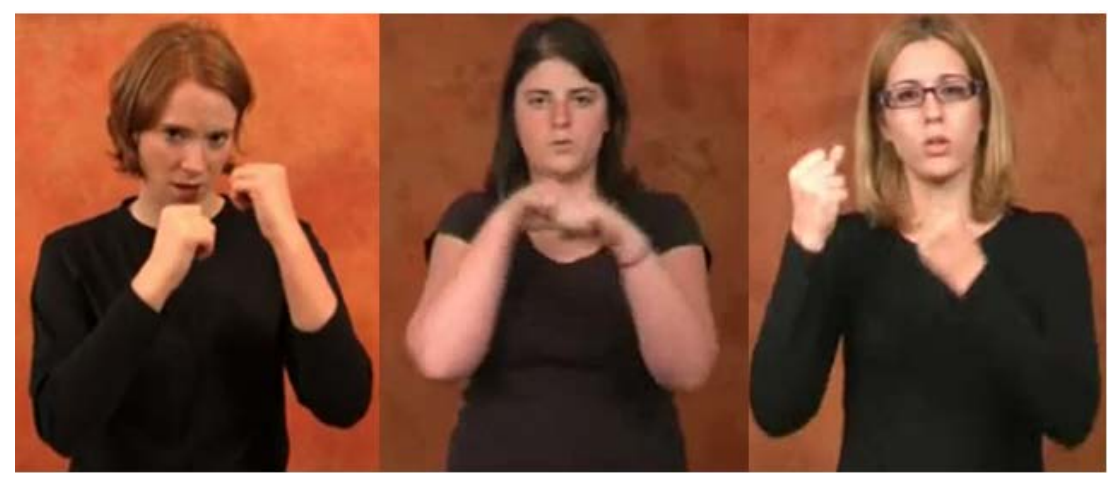

Figure 5. Comparison of the sign Boxing in American (ASL), French (FSL) and Spanish (SSL) sign languages. Movements that are not strictly consistent with the sport.

\section{Final Considerations}

In this work we find only 10 signs in LIBRAS when searching for the 33 Olympic sports in a Brazilian dictionary. Misrepresentation and/or inaccurate signs were found, suggesting the need of a more profound study about these signs to guarantee the quality of teaching Physical Education for the deaf community. Among the 23 sports without sign in LIBRAS online dictionary there included the Artistic Gymnastics and Sailing, sports in which Brazil has had great representation at sporting events. This result points to the urgent need of creating new signals or make them accessible in case of already existing. Our recent work reported the creation of these signs that will be available online soon (Barboza, 2015).

LIBRAS is important to the life of the Brazilian deafs, contributing to the formation of their identity, culture and understanding of the world. When it comes to Physical Education and sports, the correctness of these sign language is even more important as it involves health issues. Our work intends to be aware about the necessity of creating and/or organize Brazilian signs in the area of Physical Education, providing to the deaf community not only education but also stimulation for a healthier behavior.

Finally, as Brazil will hold the Olympics games in 2016, this will turn this topic into a more schoolar issue needing LIBRAS for approaching it with deaf students. Therefore, according to our data, correct and precise signs about this topic are still in need for worldwilde knowledge.

\section{Acknowledgements}

We thank to FAPERJ, CAPES, and CNPq for the fellowships and financial support.

\section{References}

Barboza, C. F. S. (2015). Physical Education, Sports And The Brazilian Signs Of Language (LIBRAS, LSB): Development Of Surdesportes Glossary For Accessibility And Inclusion Of Deaf Community. Essay defendend in 2015 at Pos-Graduation Course in Diversity and Inclusion, Niterói, RJ: Federal Fluminense University.

Brazil (2002). Law No. 10,346, dated April 24, 2002. Disp and on Brazilian Sign Language—Libras and Other Measures. Official Gazette, Brasilia 25 April 2002.

Brazil (2000). PARAMETERS NATIONAL CURRICULUM: Physical Education/Primary Education Department (2nd ed.). Rio de Janeiro: DP \& A.

Ferreira, E. L. (2011). Inclusive Physical Activities for People with Disabilities. Mogi das Cruzes: Brazilian Confederation of Wheelchair Dance.

Frydrych, L. A. K. (2012). Revisiting the Concepts of Arbitrariness and Iconicity: Implications for the Linguistic Status of Sign Languages. ReVEL, 10, 282-294. www.revel.inf.br

Gomes, M. C. (2008). The Current Panorama of Deaf Education. In the Wake of a Bilingual Education. The INES and the Deaf Education in Brazil. Vol 01, 2nd edition (Dec/2008), Rio de Janeiro: INES/2008.

Quadros, R. M., \& Perlin, G. (2007). Deaf Studies II. Petropolis: Ed. Arara Azul.

WHO (2015). Global Strategy on Diet, Physical Activity and Health. http://www.who.int/dietphysicalactivity/pa/en/ 